\title{
CULTURAL DIPLOMACY IN INTERNATIONAL RELATIONS
}

\author{
Katerina Papaioannou \\ University of Patras, GREECE, papaioannou.kat@gmail.com
}

\begin{abstract}
The main objective of this study is to highlight the upgraded role of culture in the policy of each country participating in the modern international system. The contribution of culture in policy making strategies is particularly promoted by the development of cultural diplomacy, which plays an important role in current international relations. Cultural diplomacy is an instrument of crucial importance for the transmission of culture and national values. The main role of cultural diplomacy is to promote the trans-national dialogue between different cultures and nations, particularly between the West and the Muslim world. The motivation for this study has been the fact that over the last decades several events (for instance, modern wars that have been influenced by ethnic, cultural and religious beliefs) highlighted the emergence of the critical role of culture in modern international politics.

In this study, emphasis is placed on the goals and aspirations of developing cultural diplomacy. Cultural diplomacy can be conveniently used as a flexible and universally accepted means of approaching countries with which diplomatic relations are tense or, sometimes, even non-existent. After World War II, the structure of international relations underwent significant changes and a growing tendency towards cultural disagreements was observed. In this context, it seems that culture has evolved to a powerful factor in the field of international relations, a factor of continuously increasing influence and importance. Modern developments in the field of international relations show that the 21st century will be a golden age for the further development of cultural diplomacy.
\end{abstract}

Keywords: Culture, cultural diplomacy, international relations.

\section{INTRODUCTION}

Cultural diplomacy plays an important role in current international relations, which are characterized by cultural conflicts, and is a key instrument for both the transmission of culture and national values and the ability to hear what other cultures of the rest of the world are emitting. The main objective of cultural diplomacy is to promote transnational dialogue among different cultures and nations, especially between the West and the Muslim world. Cultural diplomacy is not exclusively exercised by nation-states, since they are not the only actors on the international scene, but is also exercised by non-state actors who play a leading role in this field (Bound, Briggs, Holden, Jones, 2007).

In recent decades, there have been many events that have contributed to the emergence of the critical nature of the cultural dimension of modern international politics, including modern wars that have been 
strongly influenced by ethnic, cultural and religious beliefs. Issues that have been widely addressed include the conflict of civilizations, terrorist attacks due to religious reasons, the growing importance of elements of "soft power" in modern diplomacy, as well as the impact of communication and information technology on relations between peoples and governments.

\section{THE ROLE OF CULTURAL DIPLOMACY IN INTERNATIONAL RELATIONS}

Culture has become a diplomatic tool, a bridge needed to promote mutual understanding between nations. Gradually, more and more governments are giving priority to culture in foreign policy and diplomatic relations. The goals and aspirations stemming from the development of cultural diplomacy are first of all to create a "trust base" with other peoples, on which policy makers will then be able to achieve political, economic and military agreements. Within this emerging framework of trust, the ultimate goal is also to create among the peoples such relationships characterized by stability beyond the changes of political leadership. The role of cultural diplomacy should also be to create an agenda that will support state cooperation regardless of the political differences that may arise. Furthermore, an additional objective focuses on the development of a neutral platform so that ordinary people can communicate with each other. Cultural diplomacy can be conveniently used as a flexible and universally accepted means of approaching countries with which diplomatic relations are tense or sometimes non-existent, thus further contributing to the promotion of the development of civil society (Jaramillo Jassir, 2015).

Regardless of the state implementing it, the three most fundamental objectives of cultural diplomacy are the protection of national identity, strengthening of the prestige of a country and the promotion of mutual understanding. The protection of national identity has to do with the right of cultural self-determination of States, which is also the basis of the UNESCO Declaration on the Principles of International Cultural Cooperation (November 4, 1966). Strengthening of the prestige of a country is based on the country's desire to strengthen its position and prestige in the world. It is generally accepted that a country can shape a good image abroad by spreading its culture, values and traditions. Promoting mutual understanding between countries and individuals is based on the idea that ignorance and a lack of understanding lead to hostility among the peoples while fighting against them lead to world peace. This is why exchange programs and scholarships have been established in the field of education, placing particular emphasis on language learning and spreading in order to promote understanding among the peoples.

For a long time, state bodies were the main actors in cultural diplomacy, since they largely monopolized the management of foreign affairs, which was considered to be their "specialized field" of action. However, since the Second World War, the structure of international relations has undergone significant changes. During this period, new diplomatic factors (governmental and non-governmental) have been presented and at the same time a dramatic development of information and communication technology has taken place. However, this wind of change continued, as cultural and religious differences between countries, especially between the Muslim and the Western world, increased. This, in turn, led to the creation of universities and research centers that played a key role in cultural diplomacy (Deutsch, 1988).

The 21 st century has been characterized by the ever-increasing presence of cultural disagreements between the Muslim and the Western world. Several factors contribute to the current cultural tensions between the two worlds. These factors include migration, terrorism, the foreign policy of some Western countries on the Muslim world, the concept of freedom of speech and the press, and the limitations of religious freedom in both worlds. These rivalries have often reached critical levels and have thus highlighted the vulnerability of relations between the two worlds.

Academics and politicians on both sides in their quest to analyze the situation have focused their interest on different points. Some analysts have identified cultural factors as the main source of current and future conflicts. According to Samuel Huntington, the differences between cultures are not only real, but they are also essential. Cultures differ from each other on issues of history, language, culture, tradition and, above all, religion. Huntington concludes with pessimism that the clash of cultures will dominate the global political arena, and that the lines of fissures between cultures will be the lines of the battles of the future (Huntington, 1993). However, the majority remains optimistic about the future of humanity and chooses to emphasize the common denominators of nations that can enhance mutual understanding and trust. A large proportion of intellectuals in the world support the existence of a "dialogue between cultures" as a possible solution to the problems that have emerged, considering the multitude and diversity of the cultures and religions of the world as something normal. Following similar lines, many scientists have focused their attention on a call for an "alliance of cultures" as an alternative to the conflict of cultures. For example, in 2005, an international association called "The Alliance of Civilizations" (AoC) was set up to improve understanding and cooperation between nations and peoples of all cultures and religions, as well as to contribute to address and face forces that strengthen polarization and extremism 


\section{CONCLUSION}

In conclusion, the changing nature of international politics has altered the scene having increased the importance of intangible forms of power. Consequently, culture has become a powerful card in the field of international relations, with a continuously increasing influence and importance. In the past, governments used culture as a tool to support political and economic goals. Nowadays, culture is considered to be one of the three interdependent pillars (politics/security, economy/trade and culture) of the foreign policy system. Culture is forms a focal point of the diplomatic agenda of both state and non-state actors. Modern developments in the field of international relations show that the 21 st century will be a golden age in terms of the importance of cultural actors in relations between nations.

\section{REFERENCE LIST}

Bound, K., Briggs, R., Holden, J., Jones, S., 2007. Cultural Diplomacy. Demos, London, UK.

Jaramillo Jassir, M., 2015. Poder Blando y Diplomacia Cultural. Universidad del Rosario, Colombia.

Deutsch, K., 1988. The Analysis of International Relations. Prentice Hall, USA.

Huntington, S., 1993. The Clash of Civilizations. Foreign Affairs, 72(3), pp. 22-49. 